\title{
Morphological changes in the Qinzhou Bay, Southwest China
}

\author{
Dong $\mathrm{Li}^{1,2} \cdot$ Cheng Tang ${ }^{1} \cdot$ Xiyong Hou ${ }^{1} \cdot$ Hua Zhang ${ }^{1}$ \\ Received: 20 June 2017 /Revised: 12 January 2018 / Accepted: 8 February 2018 / Published online: 12 March 2018 \\ (C) Springer Science+Business Media B.V., part of Springer Nature 2018
}

\begin{abstract}
Morphological change in the Qinzhou Bay (QZB), southwest China, has been studied, using bathymetric charts and remote sensing data. Historical admiralty charts were digitized and analyzed in a Geographical Information System (GIS) environment to provide quantitative estimates of underwater topography changes for exploring the accretion-erosion characteristics from 1960s to 2010s. Multi-temporal satellite images have been used to analyze the coastline developments. The results showed that the bathymetry and coastline of QZB changed dramatically in recent decades. The subaqueous area decreased by about $8 \%$ in the study area during the last 50 years, mainly due to coastal land reclamation. The average growth rate of the coastlines was $2.07 \mathrm{~km} /$ yr. between 1978 and 2013 with natural curvy coastlines being replaced by straighter artificial shorelines. During the period from 1960s to 1990s, the evolution of QZB was mainly governed by natural factors with slight deposition or erosion in the deep troughs. From 1990s to 2010s, intensive large-scale human activities, such as port building, channel dredging and artificial island construction became the main causes affecting morphological changes in the QZB. Approximately half of the underwater terrain had undergone significant changes (greater than $\pm 0.5 \mathrm{~m}$ ), and the proportion of deposition area accounting for $32.26 \%$ of the subaqueous area, about twice more than erosion area. Large scale reclamation projects have made dramatic negative impact on coastal natural ecosystem. Integrated coastal zone management need to be carried out to maintain the balance between economic development and ecological health.
\end{abstract}

Keywords Morphological change $\cdot$ Admiralty charts $\cdot$ Coastline $\cdot$ Land reclamation $\cdot$ Qinzhou Bay

\section{Introduction}

Estuaries are interfaces between fluvial upland systems and wave or tide-dominated regimes of the open coast, resulting in complex sediment- and morpho-dynamics (Dai et al. 2016; Van der Wal et al. 2002). River flow, mean sea level, sediment discharge, wave fields and tide currents are generally the major factors controlling the long-term geomorphologic changes within estuarine environments (Elias and van der Spek 2006; Thomas et al. 2002; Wang et al. 2013; Wheeler et al. 2010). Recently, human activities, such as channel dredging, sand

\section{Cheng Tang}

ctang@yic.ac.cn

$\triangle$ Hua Zhang

hzhang@yic.ac.cn

1 Key Laboratory of Coastal Zone Environmental Processes and Ecological Remediation, Yantai Institute of Coastal Zone Research, Chinese Academy of Sciences, 17 Chunhui Rd,

Yantai, Shandong 264003, China

2 University of Chinese Academy of Sciences, Beijing, China mining, port expansion and artificial islands construction, increased markedly with the intensive coastal development, and gradually became a significant factor contributing to the morphological change (Blott et al. 2006; Klingbeil and Sommerfield 2005; Tonis et al. 2002). It has been reported that most maritime area in the world is affected by human activities, of which $41 \%$ is heavily impacted by multiple anthropogenic perturbations (Halpern et al. 2008). Chinese coastal areas are among the most densely populated regions in the world. Over the past few decades, reclaiming land from the sea has become a popular and effective method of managing land shortages and developing the coastal economy in coastal provinces and metropolises (Tian et al. 2016; Hou et al. 2016). The Qinzhou Bay (QZB), southwest China is no exception. With the rapid economic progress in recent decades, the morphology of the QZB has changed greatly due to intensive human interventions, such as harbor construction, bonded port (BP) building and highway construction. Morphological changes of the estuary or coastal bay can have important consequences for coastal environments (Wang et al. 2013). There is an ever increasing need for understanding their morphological changes, both to underpin environmental and 
socio-economic impact assessments and to assist in the development of effective management measures that will contribute to our responsible stewardship of the marine environment and the sustainable use of its resources (Diesing et al. 2014).

Dynamic changes of the estuary or bay system are the focus of coastal engineers and researchers due to its importance to economy development and ecosystem health. Numerous studies were carried out to reveal the coastal dynamics using laboratory experiments, hydrological investigations, analytical methods and numerical models (Kim et al. 2006; Pittaluga et al. 2015; Tambroni et al. 2005; Todeschini et al. 2008). Process-based models are used to study morphological changes quantitatively, including short-term and long-term changes (Green et al. 2000; Karunarathna and Reeve 2008). Short-term and more local scale changes can often be satisfactorily predicted using hydrodynamic and morphodynamics models. Long-term geomorphologic evolution can be simulated using statistical models such as Historical Trend Analysis (HAT) and Expert Geomorphological Assessment (EGA) (Blott et al. 2006; Townend 2005; Wang et al. 2013). At present, the analyses of historical data such as bathymetric charts and remote sensing data, GIS integration and field measurements are still effective way to quantify the long-term morphological changes (Blott et al. 2006; Van der Wal et al. 2002; Wang et al. 2013; Zhang et al. 2015).

Historical admiralty charts can give evidence on the topography in different time periods (Van der Wal and Pye 2003). Analysis of these data can help to quantify the long-term geomorphologic evolution, and to determine quantitative relationships between geomorphology and water/sediment dynamics (Blott et al. 2006; Van der Wal and Pye 2003; Wang et al. 2013). The bathymetric charts could be digitized in a Geographical Information System (GIS) and the data are recorded, stored and analyzed to build an underwater Digital Elevation Model (DEM) for further spatial analysis. Modern remote sensing methods have advantages over conventional field survey techniques, which are laborious and costly. Remote sensing and GIS technique have been used to monitor shoreline changes, to map different land uses, to detect the spatial characteristics of coastal landforms, and to identify the impacts of both natural processes and human interventions on marginal sea (Everitt et al. 2008; Hoang et al. 2016; Kumar et al. 2010; SHI et al. 2002). Landsat, which consists of a series of satellite belonging to the Earth Resource Observation System (EROS), offers the longest continuous global record of the earth's surface (Tian et al. 2016). Time series remotely sensed images with a medium spatial resolution can be used for monitoring coastline changes to study the recession and progradation for a large coastal area.

Understanding the long-term subaqueous morphodynamics and coastline changes in the coastal zone is of great value. The knowledge provides insights to the historical morphological characteristics and facilitates the predication of future evolution. It helps to assess the impact of natural evolution and anthropogenic activities on the coastal system and provide a guideline for developing effective coastal management practices. The objectives of this paper are 1) to characterize the long-term morphological changes in the QZB area located in southwest China combining historical charts and satellite images and 2) to evaluate the relative importance of different mechanisms of morphological changes.

\section{Study area}

QZB located on the coast of Guangxi Province, southwest China, extends from $21^{\circ} 33^{\prime} 20^{\prime \prime} \mathrm{N}$ to $21^{\circ} 54^{\prime} 30^{\prime \prime} \mathrm{N}, 108^{\circ} 28^{\prime} 20^{\prime \prime}$ $\mathrm{E}$ to $108^{\circ} 45^{\prime} 30^{\prime \prime} \mathrm{E}$, occupying an area of approximately $380 \mathrm{~km}^{2}$. The QZB was formed under the control of geological structure during the postglacial transgression (Zhang et al. 2010). It appears in a dumbbell shape and consists of three parts: the inner semi-enclosed bay (Maowei Sea), the funnelshaped outer bay (QZB) and the connecting tidal inlet (Wang et al. 2014). The QZB, surrounded by land on three sides (east, west, and north), is connected to Beibu Gulf in the south (Fig. 1). Qinjiang River and Mao Lingjiang River in the north flow into the Maowei Sea. Qinjiang River, with a length of $179 \mathrm{~km}$, has $2457 \mathrm{~km}^{2}$ basin area, while Mao Lingjiang, with a length of $121 \mathrm{~km}$, has $1949 \mathrm{~km}^{2}$ basin area. The lithology of both the river sides is dominated by mudstone, argillaceous siltstone and sandstone ( $\mathrm{Li}$ et al. 2001). Sediment transported by the two rivers is deposited near the estuary and continuously extended seawards, which forms a large amount of sandy and muddy shoal (Li et al. 2001). The hydrodynamics of this region is dominated by regular diurnal tidal currents and the tidal range with a mean value of $2.4 \mathrm{~m}$. The water depth (from 0 to $20 \mathrm{~m}$ ) gradually increased from north to south. A variety of underwater geomorphology was formed as a result of coastal rivers and ocean hydrodynamics interaction. The underwater geomorphology mainly includes: intertidal shoal, sand bar, tidal creek, tidal sand ridge, scouring channels and subaqueous slope ( $\mathrm{Li}$ et al. 2001). The seabed, affected by different hydrodynamic conditions significantly is primarily composed of sandy and muddy sediments. Based on data availability, a part of the QZB was chosen as our study area (Fig. 1) to reveal the morphological changes in recent decades.

Qinzhou harbor (QZH), with throughput over 8 million tons, has been one of the most important sea harbors connecting southwestern China's inland and the Southeast Asian countries (Wang et al. 2014). The QZH was constructed in 1990s and was listed one of national open ports in the year of 1997. To accommodate large ocean ships, channel dredging were performed with a great quantity of sediments removed. Today, the east channel is $12.3 \mathrm{~m}$ in depth and $120 \mathrm{~m}$ in width, allowing 50,000-ton level ship to access. The construction of 
Fig. 1 Location of the study area in the northern of Beibu Gulf. The abbreviations marked in the figure are indicated: Maowei Sea (MWS), Qinzhou Bay (QZB), Qinzhou Harbor (QZH), Bonded port (BP) and Sandun Island (SDI)

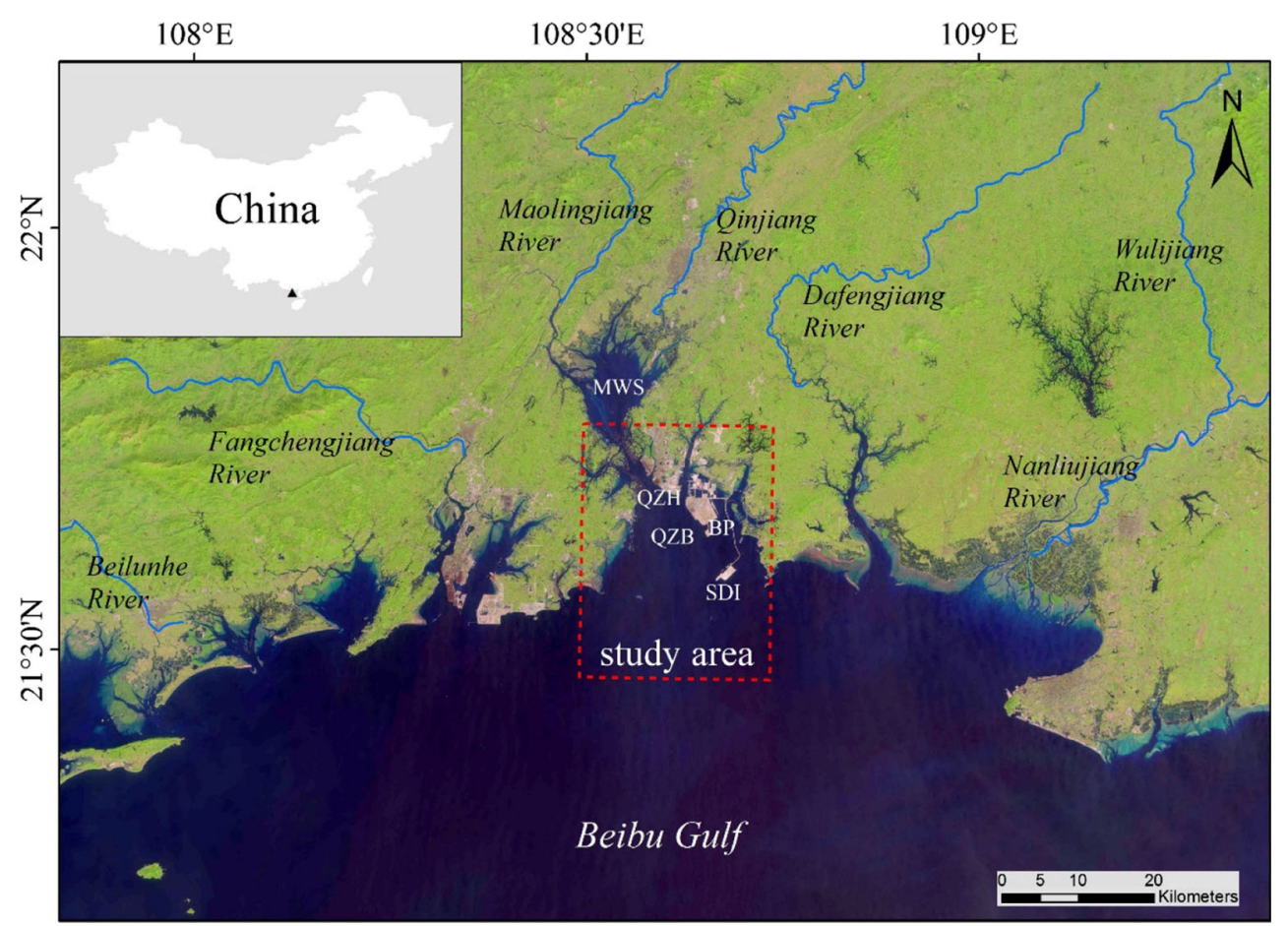

coastal structures for industry and transportation has caused serious interruption to the morphodynamic of the QZB. BP and warehouse were built during 2005-2008, while Sandun highway (SDH) and the artificial island have been under construction since 2010. By the end of 2013, overall area of land reclamation had been $22.5 \mathrm{~km}^{2}$ and planned land reclamation area will be about $79 \mathrm{~km}^{2}$ by the year of 2025 according to the municipal plan.

\section{Data and methodology}

\section{Collection and processing of admiralty charts}

To quantitatively estimate the morphological changes in this area, the historical time series of admiralty charts are collected in this study (Fig. 2). Details of 4 admiralty charts are given in Table 1. Early charts generally resulted from a single survey, completed in a single year (such as the 1970 chart). Later charts (such as the 2015 chart) were composite, based on several surveys of different date.

Errors due to measurement technique, sampling strategy, and errors made during compilation of the charts may exceed the actual change when using these charts to quantify longterm morphological development (Van der Wal and Pye 2003). However, they are generally not considered as large enough to cause serious calculating errors due to the maturity of the technology (Wang et al. 2013). Therefore, the historical bathymetric data can provide a reliable indication of relative net accretion and erosion trends during different time periods
(Blott et al. 2006). Using the latitude/longitude information, the nautical charts were geo-referenced into the UTM-WGS84 coordinates of China. Then the contours, spot depths and bay outlines were digitized to the same datum in ArcGIS v10.2 software (ESRI, USA). A Kriging method with a linear variogram and best-fit slope was used to interpolate the sparse bathymetry data, for building an underwater grid DEM with $100 \times 100 \mathrm{~m}$ cells. The DEM of the QZB was built for the quantitative analysis of the isobaths evolution, scour and silting developments. In this paper, a conservative approach was taken, the same as previous researches which suggested changes in height of over $\pm 0.5 \mathrm{~m}$ between two subsequent charts are considered significant (Blott et al. 2006; Van der Wal et al. 2002; Zhang et al. 2015). Different periods of bathymetric datasets were compared to calculate volumetric changes with the aid of ArcGIS software through a cut-fill process.

\section{Collection and processing of image data}

Information on coastline changes over time was obtained from multi-temporal remote sensing data of Landsat satellite images, i.e. 1970s (MSS), 1980s (TM), 1990s (ETM+), 2010s (ETM+) for QZB region (Fig. 3). The images selected were acquired at approximately the same time of the year. The spatial resolutions are $80 \mathrm{~m}$ for MSS images, and $30 \mathrm{~m}$ for TM and ETM+ images. Geometric correction is necessary in order to remove geometric anomalies and create a faithful representation of the original scene by correcting pixel location errors and establishing a correspondence between ground features and their correct position throughout the image 
Fig. 2 Historical admiralty charts collected to estimate morphological changes in the study area: a 1965; b 1979; c 1995/1996; d 2014
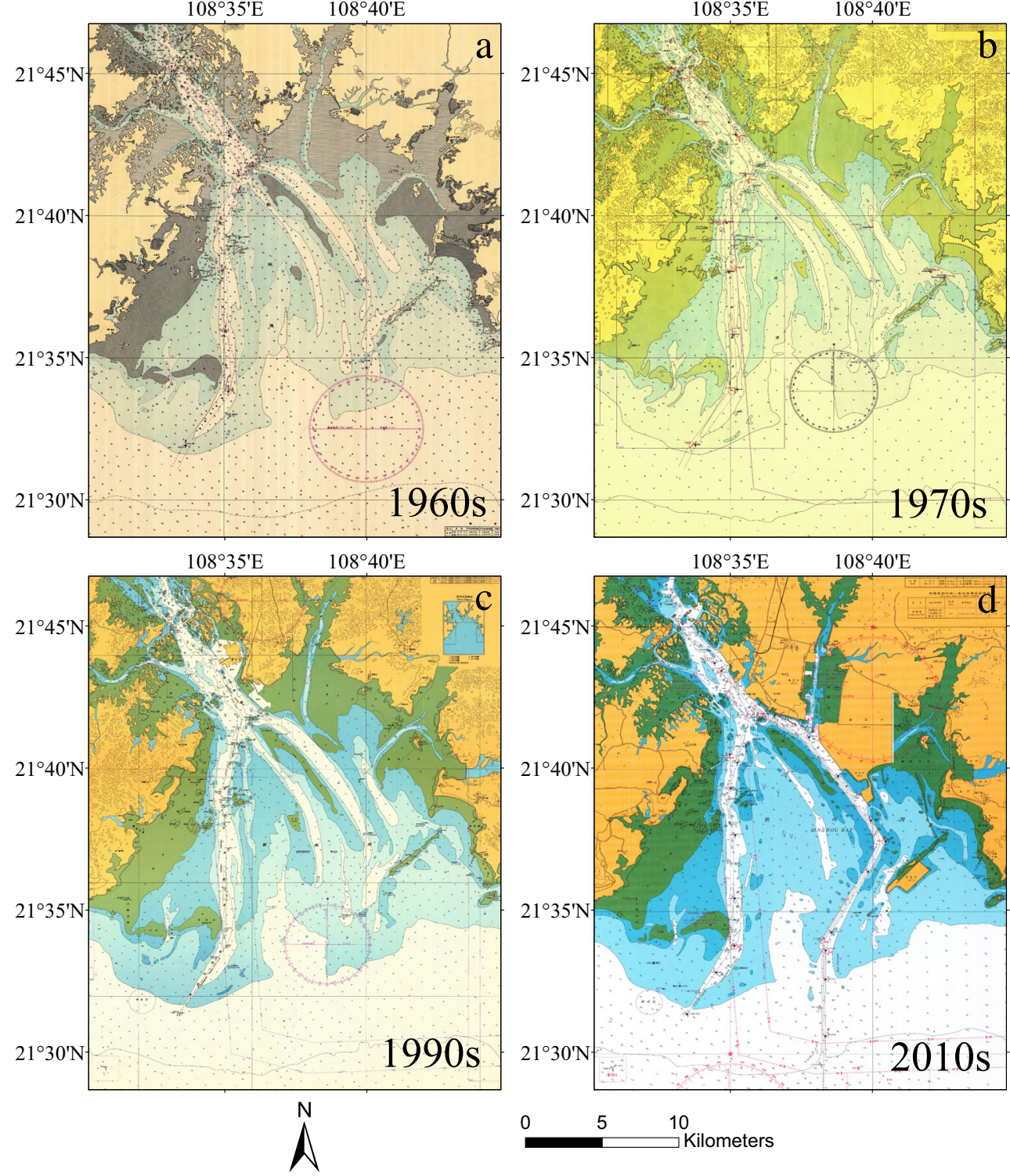

(Ahmed et al. 2009). A number of ground control points (GCPs) were identified from each image and the 1:50,000 topographical maps. The overall accuracy of the transformation, which was expressed as the root mean square (RMS)

Table 1 Admiralty charts used in the study

\begin{tabular}{lllll}
\hline Publisher & Chart No & PublishDate & SurveyDate & Scale \\
\hline NGD & 10,803 & $1970 / 10$ & 1965 & $1: 50,000$ \\
NGD & 16,781 & $1985 / 09$ & 1979 & $1: 40,000$ \\
NGD & 16,781 & $2000 / 03$ & $1995 / 1996$ & $1: 40,000$ \\
MSA & 92,101 & $2015 / 01$ & 2014 & $1: 60,000$ \\
\hline
\end{tabular}

NGD means the Navigation Guarantee Department of the Chinese Navy Headquarters

MSA means Maritime Safety Administration of the People's Republic of China error for geo-referenced images, was less than 0.5 pixels. Then a bilinear interpolation method was used to rectify and resample the images into the same geographical coordinates of UTM-WGS84 of China with the ERDAS Imagine v9.2. According to prior knowledge about morphological features, the coastlines were delineated manually in ArcGIS v10.2 at the same scale to ensure accuracy from each satellite image in this study. When coastlines extraction finished, the length of the coastline of each period was counted for analyzing the coastline developments.

\section{Limitations of used data}

Many researchers have used admiralty charts and remote sensing images to analyze sediment volumetric changes and the recession and progradation of coastlines to study the estuary or bay morphological changes (Blott et al. 2006; Lane 2004; 
Fig. 3 Comparison of the QZB study area in 4 times: a 1978; b 1987; c 1999; d 2013.

Morphological changes were clearly shown with the use of multi-temporal Landsat images. The abbreviations marked in the figure are indicated: Qinzhou Bay (QZB), Qinzhou Harbor (QZH), Bonded port (BP) and Sandun Island (SDI)

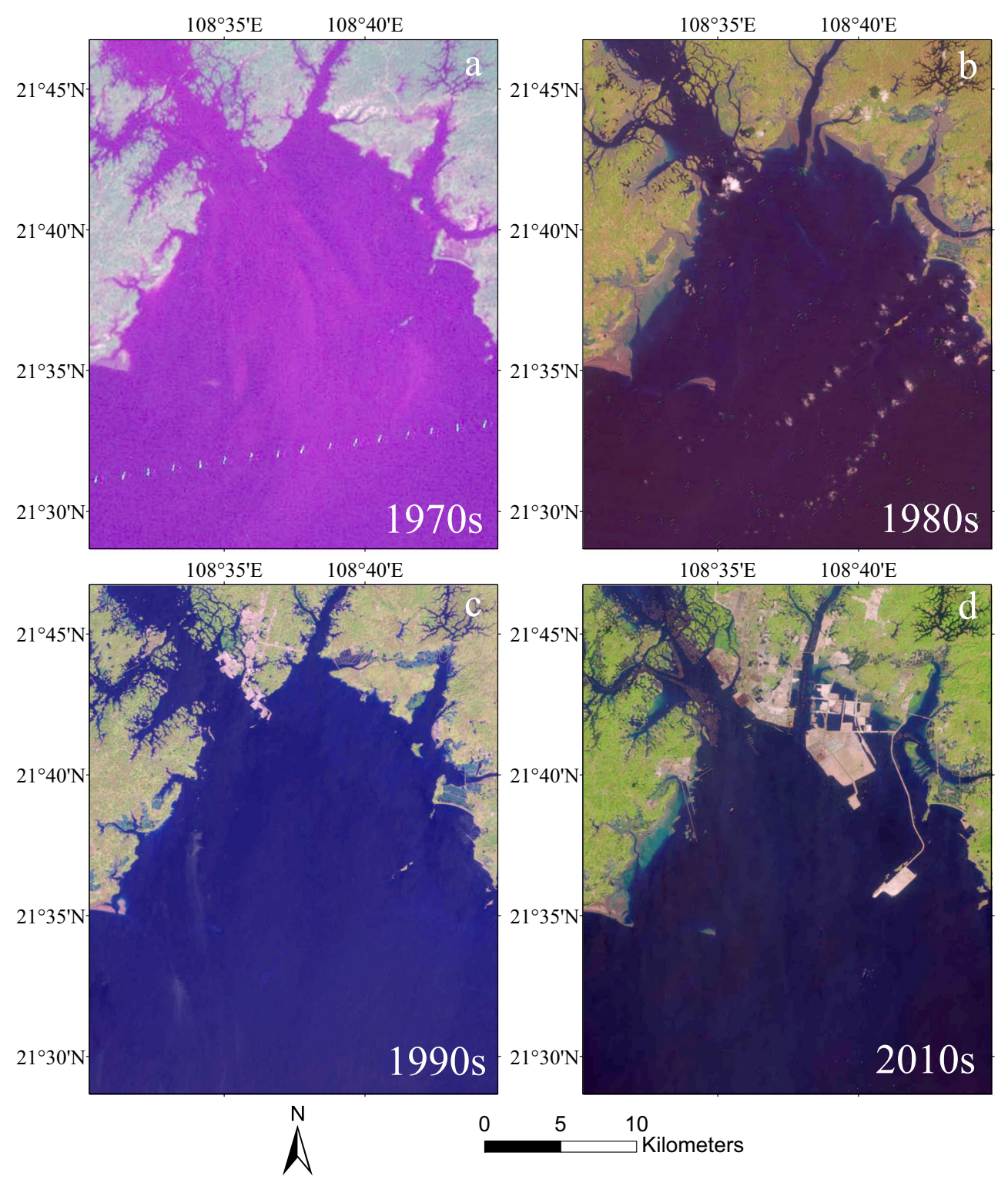

Van der Wal et al. 2002; Wu et al. 2016; Zhang et al. 2015). However, navigational charts and satellite imagery can only provide crude assessments of the morphological changes. Sources of error and uncertainty are associated with surveying techniques used, density of depth sampling points, interpolation and averaging during compilation of the charts (Van der Wal and Pye 2003). In our study, each set of spot depths was interpolated to a grid DEM with $100 \times 100 \mathrm{~m}$ cells to roughly show subaqueous terrain features. In order to obtain the detailed depth information, and to further understand the underwater topography changes caused by the construction of artificial islands for example, shipborne multibeam and airborne LIDAR survey with high resolution can be carried out at regular intervals. Errors of remote sensing data stem from the spatial resolution $(30 \mathrm{~m}$ or $80 \mathrm{~m}$ ) of satellite imagery inaccuracies. Though the error is small in comparison to the magnitude of the overall changes in coastline variations of QZB, remote sensing images with higher spatial resolution are expected to be used for the coastline extraction.

\section{Results}

\section{Variations of geomorphology in the QZB}

Fig. 4 shows the bathymetric charts (i.e. 1960s, 1970s, 1990s, and 2010s) in the QZB study area, used to estimate the subaqueous morphological changes in the region. The subaqueous topography of QZB essentially maintains a four-deeptrough configuration in recent decades: Longmen waterway (LMW), West Channel (WC), Middle Channel (MC) and East Channel (EC). The distribution of isobaths (2-m, 5-m and 10$\mathrm{m}$ ) is demonstrated in Fig. 6 and bathymetric changes (depth 
Fig. 4 Digitized bathymetry charts of QZB study area from 1960s to 2010s: a 1960s, b 1970s, c 1990s, d 2010s. The abbreviations marked in the figure are indicated: Longmen Waterway (LMW), West Channel (WC), Middle Channel (MC), East Channel (EC). Other abbreviations are the same as Fig.

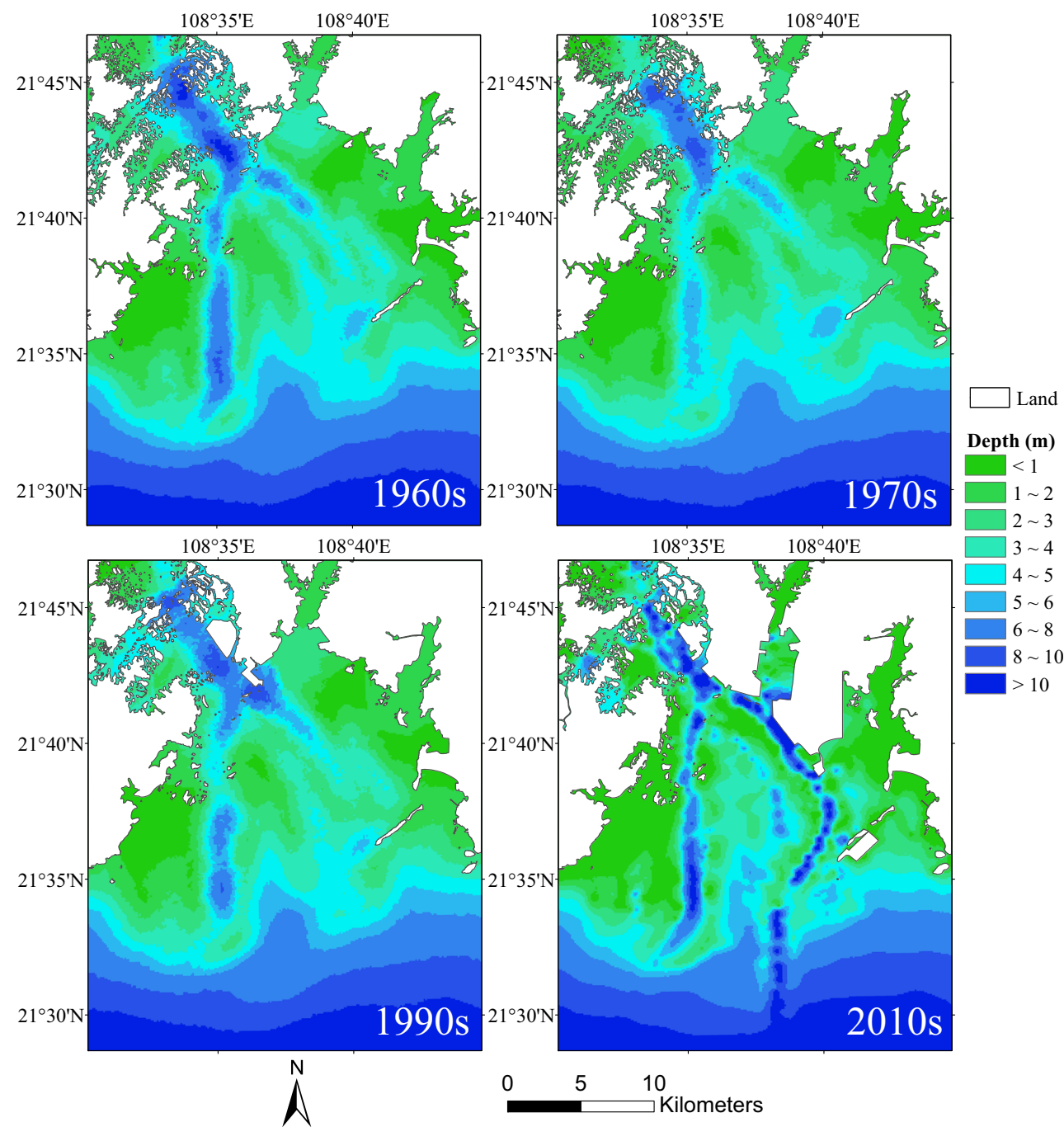

of later time minus that of the previous time) can be seen from Fig. 7.

Most 2-m isobaths were located along the coastlines and not many variations could be detected from 1960s to 1990s (Fig. 6a).
In 2010s, the 2-m isobaths near the west coast extended eastward and a number of 2-m isobaths appeared along both sides of the three channels. The 5-m isobaths were located along the channels, at the border of shoals and channels and in the outer sea.
Table 2 Changes of deposition and erosion areas and land area in the QZB study area during 1960s-2010s

\begin{tabular}{lllll}
\hline Time period & & $1960 \mathrm{~s}-1970 \mathrm{~s}$ & $1970 \mathrm{~s}-1990 \mathrm{~s}$ & $1990 \mathrm{~s}-2010 \mathrm{~s}$ \\
\hline Deposition area $\left(\mathrm{km}^{2}\right)$ & $<-3 \mathrm{~m}$ & 2.83 & 0.24 & 14.13 \\
& $-3 \sim-2 \mathrm{~m}$ & 7.93 & 1.44 & 28.97 \\
& $-2 \sim-1 \mathrm{~m}$ & 39.74 & 5.85 & 70.80 \\
& $-1 \sim-0.5 \mathrm{~m}$ & 59.20 & 28.51 & 75.99 \\
No significant change area $\left(\mathrm{km}^{2}\right)$ & $-0.5 \sim 0.5 \mathrm{~m}$ & 503.91 & 506.01 & 299.95 \\
Erosion area $\left(\mathrm{km}^{2}\right)$ & $0.5 \sim 1 \mathrm{~m}$ & 18.01 & 43.36 & 35.46 \\
& $1 \sim 2 \mathrm{~m}$ & 4.68 & 23.61 & 33.63 \\
& $2 \sim 3 \mathrm{~m}$ & 0.73 & 7.22 & 14.17 \\
Percentage of deposition area $(\%)$ & $>3 \mathrm{~m}$ & 0.11 & 5.93 & 15.55 \\
Percentage of erosion area $(\%)$ & & 17.22 & 5.79 & 32.26 \\
Land area gain $\left(\mathrm{km}^{2}\right)$ & & 3.69 & 12.88 & 16.79 \\
\hline
\end{tabular}


Compared with the past periods, more 5-m isobaths could be found in the 2010s, especially in the area along the middle and EC (Fig. 6b). There were few 10-m isobaths from the 1960s to 1990s in the study area except the outer sea. In 2010s, some 10$\mathrm{m}$ isobaths could be identified along the EC (Fig. 6c).

In general, the bathymetry of QZB was relatively stable from 1960s to 1990s and three scouring channels were shaped by tidal currents (Fig. 4a, b and c). The QZH had not been constructed before 1970s. During the period of 1960 s to 1970 s, about $80 \%$ of the sea area had no significant depth change, with nearly $17 \%$ were deposition area (Fig. $7 \mathrm{a}$, Table 2). Siltation mainly occurred in the four deep troughs. The morphology of Longmen channel and WC changed as a result of deposition of about $2 \mathrm{~m}$ and the siltation of less than $1 \mathrm{~m}$ could be detected in the northeast of LMW (Fig. 7a). The depth of sea area near Sandun Island (SDI) increased about $1 \mathrm{~m}$. From 1960s to 1970s, the average water depth in the study area decreased from $4.90 \mathrm{~m}$ to $4.69 \mathrm{~m}$ and the subaqueous area slightly shrank from $640.41 \mathrm{~km}^{2}$ to $637.1 \mathrm{~km}^{2}$ (Fig. 5). Like the period of 1960 s to 1970 s, more than $80 \%$ of the subaqueous area had no significant depth change from 1970s to 1990s. Different from 1970s, evidence of human activities, especially near the QZH, increased in 1990s and the land reclamation area increased $14.97 \mathrm{~km}^{2}$ during the twenty years (Table 2). Compared with the 1970s, the QZH was constructed in the 1990s and it is clear to identify the harbor infrastructure from 1990s' remote sensing image (Fig. 3c), which could not be found from 1970s' (Fig. 3a). Notable dredging depth of more than $3 \mathrm{~m}$ took place at southeast of the QZH correspondingly (Fig. 7b). In this period, LMW existed in a condition of dynamic equilibrium with siltation and erosion in some areas, which was similar to the period of 1960s to 1970s. Deposition of about $1 \mathrm{~m}$ took place around SDI. Erosion of more than $0.5 \mathrm{~m}$ occupied $80.12 \mathrm{~km}^{2}$ in the study area, $12.88 \%$ of the subaqueous area (Table 2), which was more than 2 times larger than deposition area $(5.79 \%)$. Though the subaqueous area decreased $2.34 \%$, the water volume net gain was $54 \times 10^{6} \mathrm{~m}^{3}$ (Fig. 5).
With the continuous improvement of the infrastructure of QZH and the implementation of dredging and filling engineering for the construction of BP, the QZB geomorphology changed drastically from 1990 s to 2010 s. Land area increased from $210.8 \mathrm{~km}^{2}$ to $244.4 \mathrm{~km}^{2}$, while the proportion of water area decreased $5.38 \%$ in the study area (Fig. 5, Table 2). Nearly half of the underwater terrain had undergone significant changes, that is to say, the deposition and erosion area accounted for $32.26 \%$ and $16.79 \%$ of the subaqueous area respectively, which were much larger than other two previous periods. Though the average water depth remained almost unchanged, from $4.89 \mathrm{~m}$ in $1990 \mathrm{~s}$ to $4.88 \mathrm{~m}$ in $2010 \mathrm{~s}$, the water volume net loss was $169 \times 10^{6} \mathrm{~m}^{3}$ (Fig. 5). The most significant feature in 2010s was that all the three channels were deepened, the $\mathrm{WC}$ and $\mathrm{EC}$ with a depth of over $10 \mathrm{~m}$, displaying a shape of two narrow deep grooves in Fig. 4d. It could be obviously seen from Fig. 6c that the 10-m isobaths were located along the EC extending to the outer sea. The depth of the three main channels increased more than $2 \mathrm{~m}$. There were deposition areas around the west and east deepened channels with a siltation of more than $2 \mathrm{~m}$ or $3 \mathrm{~m}$ in some areas, possibly due to disposal of dredging material. Compared with the 1990s, the QZH was expanded eastward in 2010s. Near the south and west area of the harbor, a great deal of sediment was dredged out for land reclamation to improve cargo-handling capacity. As a result, the water depth increased more than $3 \mathrm{~m}$ near the harbor (Fig. 7c). Another significant change in 2010s was that the BP and warehouse were built in southeast of QZH, occupying a large portion of sea area. This change could also be easily seen from remote sensing images (Fig. 3c and d). Similar to the underwater terrain changes near QZH, the water depth near southwest of the BP increased over $3 \mathrm{~m}$ because the excavation was carried out on the basis of EC (Fig. 7c). Figures $3 \mathrm{~d}$ and $4 \mathrm{~d}$ showed that the offshore artificial island near SDI had been built with an area of about $2 \mathrm{~km}^{2}$ and the SDH, over $10 \mathrm{~km}$ long, was also completed, connecting the land and the artificial island. Areas of aggradation were created around the artificial island with a sedimentation of about $1 \mathrm{~m}$. Compared to the other
Fig. 5 a Subaqueous area of $1-\mathrm{m}$ interval in QZB study area from 1960s to 2010s. b Water area and volume of QZB study area from 1960 s to 2010 s

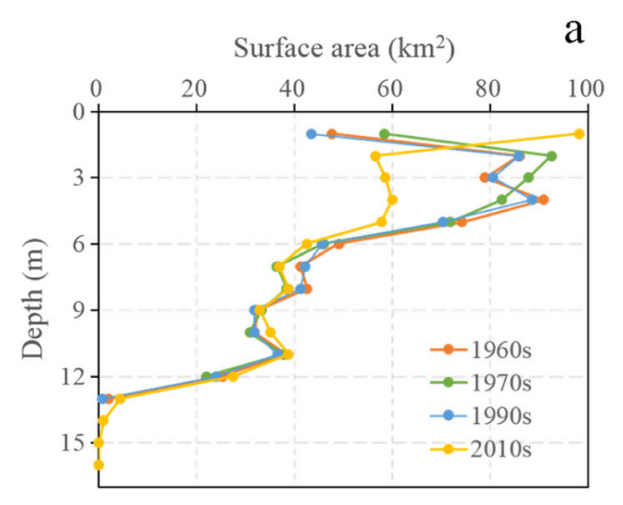

a

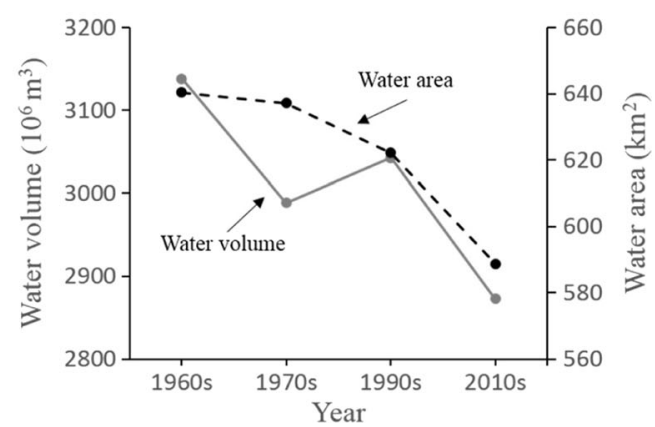


Fig. 6 Distribution of isobaths in the QZB study area of 1960 s, 1970s, 1990s and 2010s including a 2-m isobaths, b 5-m isobaths and $\mathbf{c} 10-\mathrm{m}$ isobaths. The legend describes the colored lines used to differentiate study periods
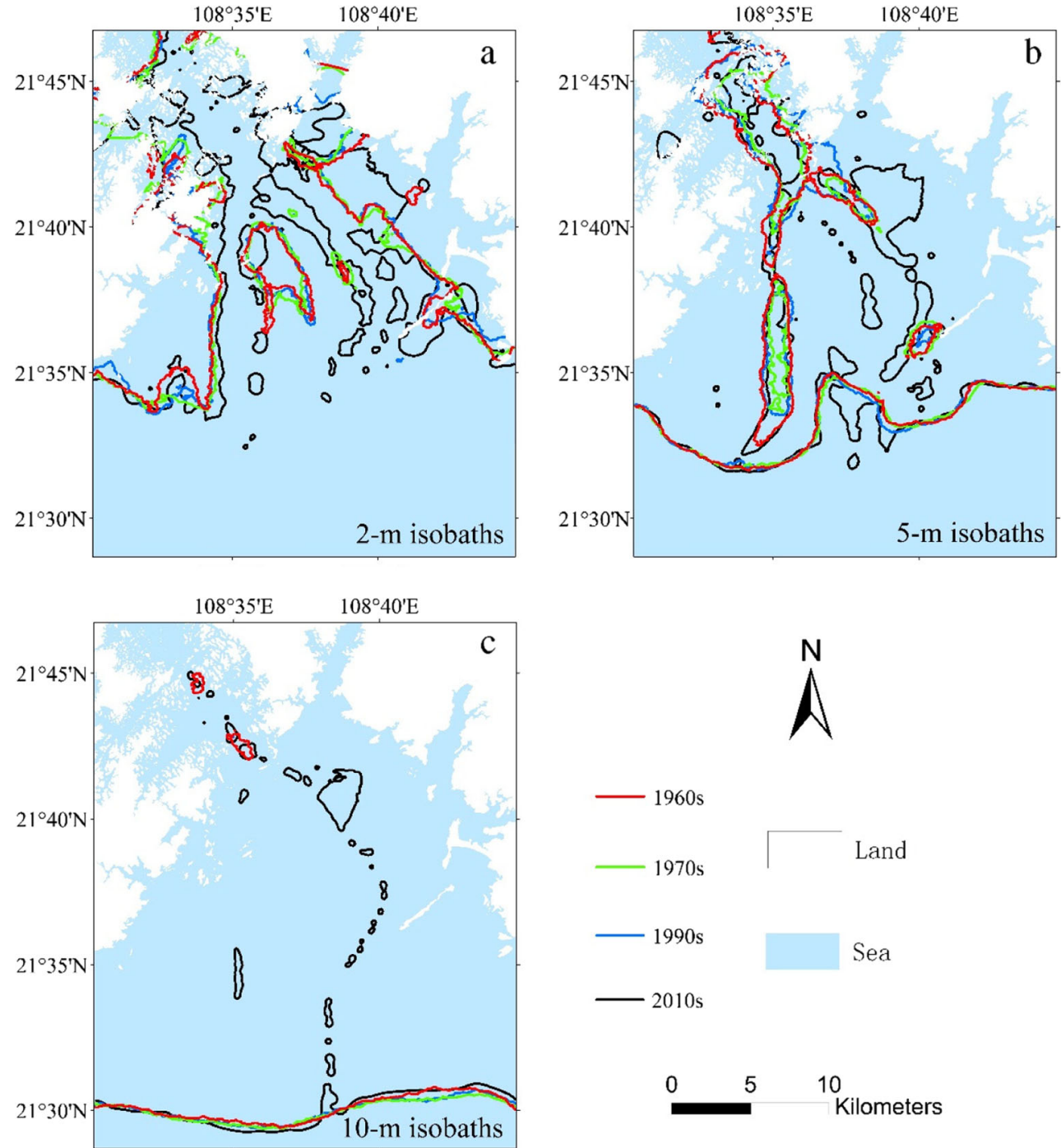
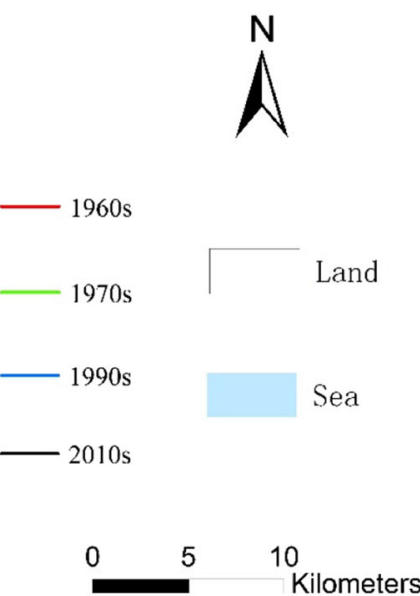

periods, there was more deposition of less than $1 \mathrm{~m}$ near the natural coastlines from 1990s to 2010s.

\section{Changes in the coastlines}

Figure 8 shows variations of the coastlines of the QZB study area during the period from 1978 to 2013 . The length of coastlines increased by about $72.4 \mathrm{~km}$ during the 35 years and the average growth rate of the coastlines was $2.07 \mathrm{~km} / \mathrm{yr}$. (Table 3). There had been no major morphological changes from 1978 to 1987 (Fig. 3a and b). In this period, the QZB was in a dynamic equilibrium and coastlines developed naturally with few signs of being related to human activities. The total length of coastlines just increased about $1.3 \mathrm{~km}$, i.e. the average extension rate was $140 \mathrm{~m} / \mathrm{yr}$. In 1990s, evidence of human activities increased markedly. Figure $3 \mathrm{c}$ showed that the QZH and the surrounding infrastructure were built, with a large portion of coastal areas converted for land reclamation. From 1987 to 1999, the coastlines grew by an average of $3.48 \mathrm{~km} / \mathrm{yr}$, about 25 times more than the rate between 1978 and 1987, and the total length increased by $20.8 \%$ in the study area. From 1990 s to 2010 s, dramatic coastline changes took place mainly in the southeast of QZH (Fig. 3c and d). In this period, the construction of BP and warehouse greatly changed the morphology of coastlines. In addition, the building of the offshore artificial island and SDH also drastically modified the coastlines. The total length of coastlines continued to increase from $241.8 \mathrm{~km}$ in 1999 to $271.2 \mathrm{~km}$ in 2013 . In recent decades, some curvy coastlines became straighter and many natural shorelines were replaced by artificial shorelines due to land reclamation.

\section{Discussion}

\section{Impact of natural environmental factors}

Several natural environmental forcing factors, such as sea level rise, tide, wave, river flow, and sediment discharge could have 
Fig. 7 Bathymetric changes (depth of later time minus that of the previous time) in the QZB study area in the following periods: a $1970 \mathrm{~s}-1960 \mathrm{~s}$, b 1990s-1970s, c 2010s-1990s. The abbreviations marked in the figure are the same as Fig. 4
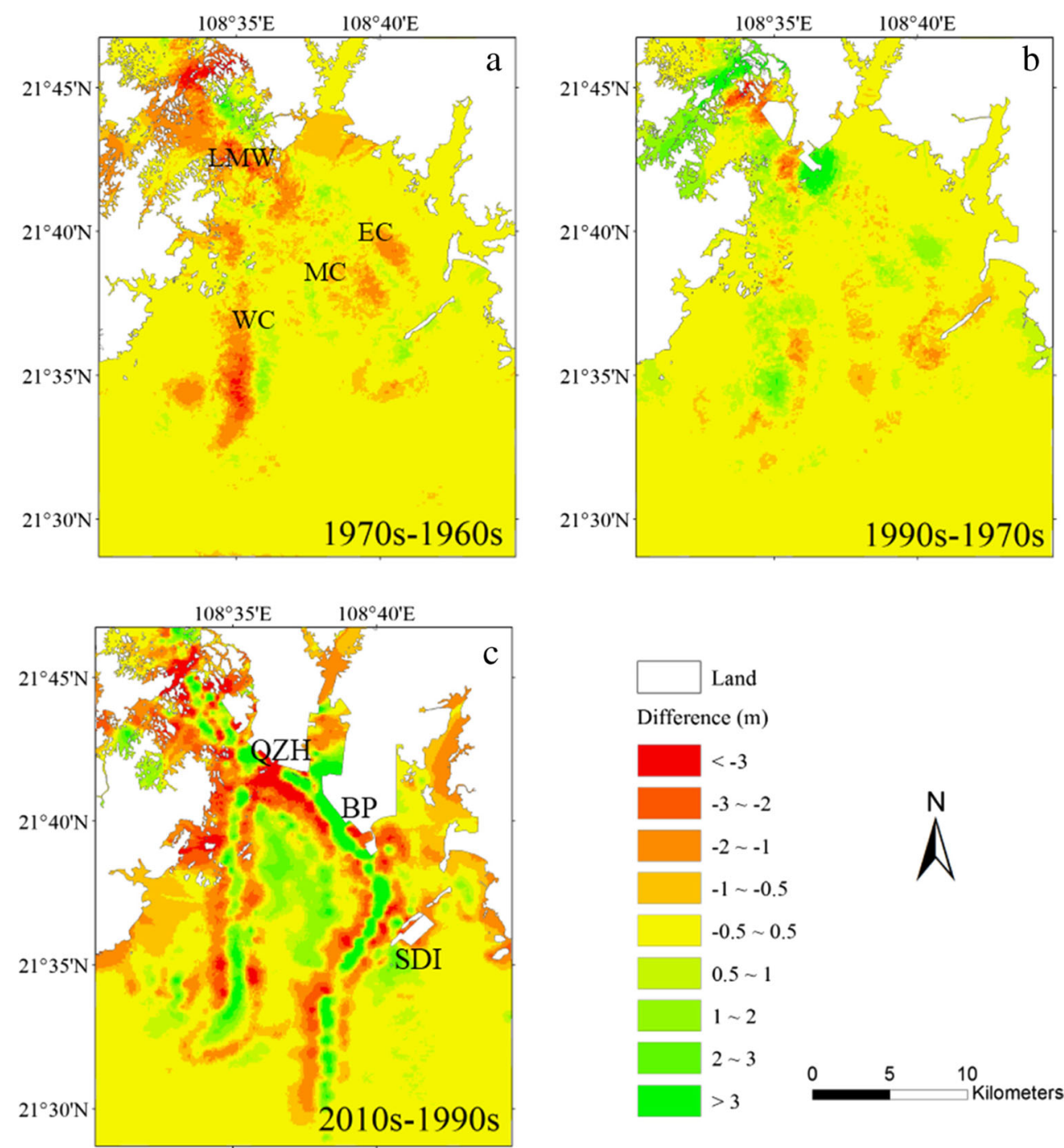

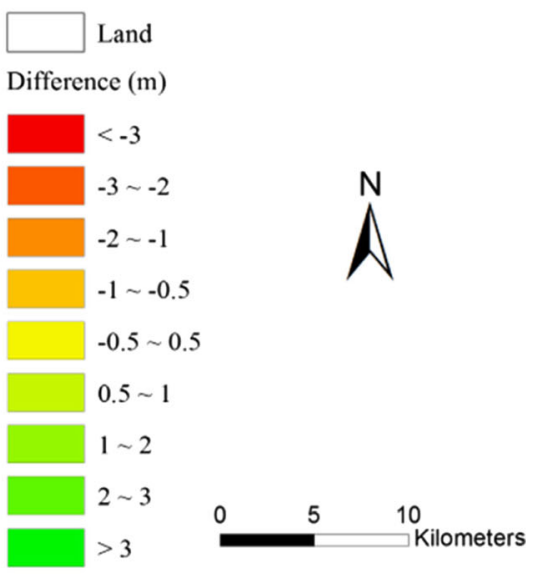

contributed to the observed morphological changes. There is observation evidence that global mean sea levels are rising (Mudersbach et al. 2013). In shallow coastal areas, wave heights, tides, and surges are strongly correlated with sea-level rise (Arns et al. 2017). The rising sea level can erode the coast and flood more land, causing coastlines subject to open-ocean conditions. It was suggested that the loss of wetlands and intertidal areas is having a significant impact on surge risk (Loder et al. 2009). The sea level along China's coastlines has risen by $2.9 \mathrm{~mm} / \mathrm{yr}$. over the past 3 decades and the mean sea levels along the coastlines of South China would probably rise by $60-130 \mathrm{~mm}$ in the next 30 years (Zhang et al. 2015). However, in QZB study area, most coastlines displayed a seaward extending tendency and the calculation indicates that the coastlines extended by $36.4 \%$ from 1978 to 2013 (Table 3). In QZB, the sea-level rise is unlikely to have played a significant role in determining the major changes in the subaqueous morphology and coastlines.

The MWS receives discharge from the Qinjiang River and Mao Lingjiang River in the north which deliver annually
$27.73 \times 10^{9} \mathrm{~m}^{3}$ fresh water and $86.4 \times 10^{3} \mathrm{t}$ sediments $(\mathrm{Li}$ et al. 2001). Most sediments delivered by the two rivers are deposited within the inner bay (MWS) with limited amount of fine particles transported into the outer bay and open sea (Wang et al. 2014). The unique features of the QZB, narrow inlet connecting the wide inner and outer bay, help to create a favorable condition for the development of the deep troughs. Measured data showed the troughs current is strong, with the maximum flow and ebb rate of $100 \mathrm{~cm} / \mathrm{s}$ and $170 \mathrm{~cm} / \mathrm{s}$ respectively, which forms a violent turbulence to scour the deep troughs (Li et al. 2001). So the deep troughs could remain stable due to the reduced amount of sediment and the strong water flow (Zhang et al. 2010). Because of the existing of the underwater rock block, the narrow LMW branched into 3 deep finger-shaped-like channels. And the tidal trough, i.e. the WC, up to $27 \mathrm{~km}$, forms a naturally deep navigation channel. Under the leading role of natural factors, the direction and distribution pattern of the deep troughs were basically unchanged from 1960s to 1990s (Fig. 4a, b and c). 


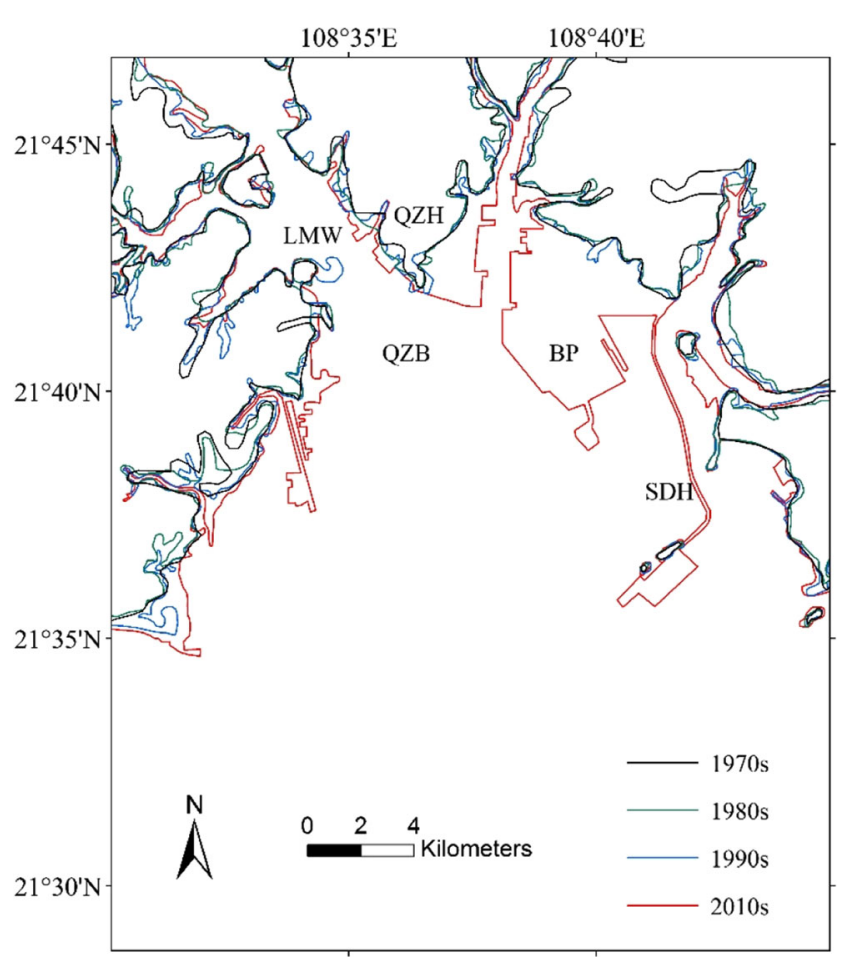

Fig. 8 Coastline evolution in the QZB study area for the period 1970s to 2010s. Colored lines represent coastline changes in different periods. SDH means Sandun highway and other abbreviations are the same as Fig. 4

\section{Impact of human activities}

There is growing evidence that the effects of major human activities on the morphological development in the past century may have outstripped that of natural forcing factor (Blott et al. 2006; Klingbeil and Sommerfield 2005; Wang et al. 2013).

Remote sensing survey and water census had been carried out several times by the Ministry of Water Resources of the People's Republic of China. The area of soil erosion in Guangxi Province increased from $12,982 \mathrm{~km}^{2}$ in 1965 to $13,564 \mathrm{~km}^{2}$ in 1975 , largely due to agriculture practices such as severe deforestation for farmland expansion (Liang 2014). As a result, during the period of 1960s to 1970s, anthropogenic effects caused appreciable increase in the sediment loads in rivers. Deposition area accounted for nearly $17 \%$ of the study area and the siltation mainly occurred in the deep trough (Fig.

Table 3 Coastline changes of QZB study area

\begin{tabular}{llll}
\hline Coastline & Length $(\mathrm{m})$ & Length change $(\mathrm{m})$ & Growth rate $(\mathrm{m} / \mathrm{yr})$ \\
\hline 1978 & $1.988 \times 10^{5}$ & & \\
1987 & $2.001 \times 10^{5}$ & $0.13 \times 10^{4}$ & $0.14 \times 10^{3}$ \\
1999 & $2.418 \times 10^{5}$ & $4.17 \times 10^{4}$ & $3.48 \times 10^{3}$ \\
2013 & $2.712 \times 10^{5}$ & $2.94 \times 10^{4}$ & $2.10 \times 10^{3}$ \\
Total & & $7.24 \times 10^{4}$ & $2.07 \times 10^{3}$ \\
\hline
\end{tabular}

7a, Table 2). Since 1980s the government have stepped up its efforts on soil and water conservation, carrying out afforestation and rebuilding reservoirs such as Lingdong and Jilong for sediment retention (Liang 2014). The flux of sediments reaching coastlines has reduced dramatically and the proportion of erosion area increased obviously (Fig. $7 \mathrm{~b}$ and c, Table 2).

The available evidence strongly suggests that dredging and dredge spoil disposal are important anthropogenic factors affecting the morphology and distribution of sediment (Blott et al. 2006). Before 1990s, the deep troughs existed in a condition of dynamic equilibrium. From 1990s, human influence overwhelmed the natural factors to change the morphology of QZB. At the end of the twentieth century, the north deep trough had been developed into the harbor and anchorage by dredging, while the east and west deep trough had been developed into inbound and outbound channels for QZH. Figure $7 \mathrm{c}$ obviously showed that the erosion areas indicate large-scale dredging activities in the deep troughs from 1990 s to 2010s. Figure 5 showed that though the water area decreased by $14.9 \mathrm{~km}^{2}$ from 1970 s to $1990 \mathrm{~s}$, the water volume increased by $54.2 \times 10^{6} \mathrm{~m}^{3}$ mainly due to channel and port dredging. With the development of maritime trade, channel dredging and expansion work were carried out regularly. Especially in 2010s, channel dredging and dredge spoil dumping significantly altered local underwater morphology, which can be identified from Figs. 4d and $6 \mathrm{c}$. The EC and WC were deepened and the 10-m isobaths of EC extended to the outer sea. Some dredge spoil was disposed on the seafloor around the channel, resulting an obvious deposition of about $2 \mathrm{~m}$ along the EC and WC (Fig. 7c). This phenomenon also appeared in Lingding Bay of the Pearl River estuary (Wu et al. 2016). Pye and Neal (1994) found that increased or decreased water depth caused by dredging and spoil dumping would influence the wave regime, contributing to a change from frontal dune accretion to erosion around Formby Point. So it is important to select the reasonable dumping areas for the dynamic balance of the channel.

Land reclamation is another one of the most important human activities that affect the morphology of bays (Dai et al. 2016; Lane 2004) and it changes the length of the coastline and the shape of land or an island in a direct way (Zhang et al. 2015). Tables 2 and 3 showed that $51.76 \mathrm{~km}^{2}$ of land was reclaimed during 1960s-2010s and the length of coastlines increased by $7.24 \times 10^{4} \mathrm{~km}$ from 1978 to 2013 . Large-scale reclamation directly leads to significant variation of the coastlines. In the QZB study area, notable coastal land reclamation began at 1990s, which can be clearly identified from satellite images (Fig. 3c). The QZH was built in 1990s and then expanded in the subsequent time, which changed the land fraction and underwater morphology because coastal sea areas turned land and the harbor was dredged and deepened accordingly. The construction of BP and warehouse began in the year 
of 2005 and gradually took up large area of sea surface (Dong et al. 2015). By 2012, the SDH and the offshore artificial island had been completed, which also brought dramatic morphological changes. The results are clearly displayed in Figs. $3 \mathrm{~d}$ and $7 \mathrm{c}$. The long highway, built in the sea, could enhance local tidal flow, which may cause sediment suspension. This has been confirmed by Dong et al. (2015), who found the sediment concentration was as high as $30 \sim 40 \mathrm{mg} / \mathrm{L}$ in the central waters of the east side of the SDH by using the numerical simulation method. The construction of the artificial island and land reclamation will affect the sediment transport, mainly through altering velocities and ultimately influencing the erosion and deposition patterns, which has been proved by Wang et al. (2013).

\section{Effects of morphological change}

Hydrodynamic environment, such as flow velocity, the current direction and so on, will be affected by morphological change, especially the vast changes between 1990s to 2010s. Ya et al. (2017) calculated the change of tidal current, tidal prism, and water exchange ability of QZB by numerical simulation method. The results showed that after the change of the shoreline, the flow velocity of the water near the top of SDH was increased by $0.2 \mathrm{~m} / \mathrm{s}$, the current direction changed from southeast to southwest near SDI in flood tide and the half exchange time of water was extended from $27 \mathrm{~d}$ to $28 \mathrm{~d}$. Numerical simulation results showed though the QZB generally exhibited stable situation, erosion and deposition environment in some waters had undergone a significant change due to large-scale reclamation, the annual erosion of the tidal flat in the middle of SDH up to $0.07 \mathrm{~m}$, for example (Dong et al. 2015). It is noteworthy that there was enhancement of accumulation in the coastal areas during the period of 1990 s to 2010s. In addition, it can be found that the WC had been migrating eastwards (Fig. 7a). It can be inferred that intensification of hydrodynamic conditions was probably caused by changes in the geometry of the channels and connected changes in erosion and sedimentation.

The QZB morphological changes not only affect the hydrodynamic environment, but also influence the regional ecosystems. For example, mangrove distribution patterns in QZB changed from highly or relatively concentrated to nearly from1960s to 2010s mainly due to the constructions of dike, aquaculture ponds and port ( $\mathrm{Li}$ et al. 2015). Based on the survey results of the marine environment in the coastal waters of the QZB from 2009 to 2011, assessment and analysis were conducted on the marine ecosystem health, indicting the marine organism index and the habitat index had reached an unhealthy status (Lai et al. 2016). Also, coastal engineering will change local habitat, causing biomes variation. In general, large scale reclamation project, such as artificial islands construction, is completed by hydraulic fill method. As a result, a great quantity of sediment was extracted from the local seafloor and it will make an impact on benthic environment both directly and indirectly (Barnes and $\mathrm{Hu}$ 2016). Zhuang et al. (2014) carried out surveys of the intertidal organism in QZB from 2009 to 2012, and found the differences of the variation of biotic communities with years change in different transects were related to the environment change derived from sea reclamation. In addition, tidal current change can affect pollutant transport. It is reported that the COD concentration increased about $10 \%$ after the BP and warehouse construction in the QZB (Gao et al. 2014).

The long-term morphological changes including the evolution of the underwater terrain as well as the shoreline in the QZB were characterized, and the different mechanisms of morphological changes were evaluated in our study. This paper can provide the necessary information to improve our understanding of the interaction between human activities and the natural environment. As discussed above, the largescale offshore development has a certain impact on the souring and silting environment and the regional ecosystem of the coastal bay. Though coastal engineering has brought huge economic benefits to the localities, its negative impact on coastal natural ecosystem cannot be ignored. Integrated coastal zone management need to be carried out to maintain the balance between economic development and ecological health.

\section{Conclusions}

Based on admiralty charts and remote sensing images, the variations of geomorphology and coastline developments were analyzed quantitatively using RS-GIS integration technology in QZB. Our study showed that the subaqueous area decreased $51.76 \mathrm{~km}^{2}$ during $1960 \mathrm{~s}-2010 \mathrm{~s}$ and the length of coastlines increased $7.24 \times 10^{4} \mathrm{~km}$ from 1978 to 2013 in the study area. The curvy coastlines became straighter and many natural shorelines were replaced by artificial shorelines. Analyzing results indicated the morphology of QZB was relatively stable from 1960s to 1990s and the geomorphology changed drastically since 1990 s due to intensive coastal developments. Anthropogenic effects have outweighed the effects of changes in natural forcing factors over the past 50 years in the QZB study area. The impact of intensive human activities, such as land reclamation, port construction and channel dredging, which are common practice in many estuaries worldwide, may be substantial and prolonged on the morphological development of QZB. The impact on the ecological environment should be regarded as an important aspect to consider in sustainable planning of the large scale reclamation project, not just to chase economic benefits. The understanding of the long-term morphological changes in the QZB has practical significance not only because the knowledge 
provides insights into the historical evolution, it also facilitates the predication of future evolution by numerical modeling. Further investigations are warranted to investigate the impact of rapid morphological changes on ecosystem health of the subtropical QZB.

Acknowledgments This work was financially supported by grants from the National Key Basic Research Program of China (973) (No.2015CB453301), the Strategic Priority Research Program of the Chinese Academy of Sciences (No. XDA11020305), and the Key Deployment Project of Chinese Academy of Sciences (No. KZZD-EW-14).

\section{References}

Ahmed MH, El Leithy BM, Thompson JR, Flower RJ, Ramdani M, Ayache F, Hassan SM (2009) Application of remote sensing to site characterisation and environmental change analysis of North African coastal lagoons. Hydrobiologia 622:147-171

Arns A, Dangendorf S, Jensen J, Talke S, Bender J, Pattiaratchi C (2017) Sea-level rise induced amplification of coastal protection design heights. Sci Rep 7:40171

Barnes BB, Hu C (2016) Island building in the South China Sea: detection of turbidity plumes and artificial islands using Landsat and MODIS data. Sci Rep 6:33194

Blott SJ, Pye K, van der Wal D, Neal A (2006) Long-term morphological change and its causes in the Mersey Estuary, NW England. Geomorphology 81:185-206

Dai Z, Fagherazzi S, Mei X, Chen J, Meng Y (2016) Linking the infilling of the North Branch in the Changjiang (Yangtze) estuary to anthropogenic activities from 1958 to 2013. Mar Geol 379:1-12

Diesing M, Green SL, Stephens D, Lark RM, Stewart HA, Dove D (2014) Mapping seabed sediments: Comparison of manual, geostatistical, object-based image analysis and machine learning approaches. Cont Shelf Res 84:107-119

Dong DX, Li YC, Chen XY, Chen B, Ya HZ (2015) Impacts of ocean engineering on shoreline, topography and deposition-erosion environment in Qinzhou Gulf. Guangxi Sci 22:266-273 (In Chinese)

Elias EPL, van der Spek AJF (2006) Long-term morphodynamic evolution of Texel Inlet and its ebb-tidal delta (The Netherlands). Mar Geol 225:5-21

Everitt JH, Yang C, Sriharan S, Jud FW (2008) Using High Resolution Satellite Imagery to Map Black Mangrove on the Texas Gulf Coast. J Coast Res 24:1582-1586

Gao JS, Chen B, Lu HS, Zhuang JL, Dong DX (2014) Numerical study on the characteristics of tidal current field and pollutant transport in Qinzhou Bay. Guangxi Sci 21:345-350 (In Chinese)

Green MO, Bell RG, Dolphin TJ, Swales A (2000) Silt and sand transport in a deep tidal channel of a large estuary (Manukau Harbour, New Zealand). Mar Geol 163:217-240

Halpern BS, Walbridge S, Selkoe KA, Kappel CV, Micheli F, D'Agrosa C, Bruno JF, Casey KS, Ebert C, Fox HE, Fujita R, Heinemann D, Lenihan HS, Madin EMP, Perry MT, Selig ER, Spalding M, Steneck R, Watson R (2008) A global map of human impact on marine ecosystems. Science 319:948-952

Hoang TC, O'Leary MJ, Fotedar RK (2016) Remote-Sensed Mapping of Sargassum spp. Distribution around Rottnest Island, Western Australia, Using High-Spatial Resolution WorldView-2 Satellite Data. J Coast Res 32:1310-1321

Hou XY, Wu T, Hou W, Chen Q, Wang YD, Yu LJ (2016) Characteristics of coastline changes in mainland China since the early 1940s. Sci China Earth Sci 59:1791-1802
Karunarathna H, Reeve D (2008) A boolean approach to prediction of long-term evolution of estuary morphology. J Coast Res 24:51-61

Kim TI, Choi BH, Lee SW (2006) Hydrodynamics and sedimentation induced by large-scale coastal developments in the Keum River Estuary, Korea. Estuar Coast Shelf Sci 68:515-528

Klingbeil AD, Sommerfield CK (2005) Latest Holocene evolution and human disturbance of a channel segment in the Hudson River Estuary. Mar Geol 218:135-153

Kumar A, Narayana AC, Jayappa KS (2010) Shoreline changes and morphology of spits along southern Karnataka, west coast of India: A remote sensing and statistics-based approach. Geomorphology 120:133-152

Lai JX, Xu MB, Zhang RC, Jiang FJ, Lei F, Tan XL (2016) Assessment and Analysis on the Marine Ecosystem Health in the Qinzhou Bay, Guangxi Autonomous Region, China. Guangxi Sci 35:102-108 (In Chinese)

Lane A (2004) Bathymetric evolution of the Mersey Estuary, UK, 1906 1997: causes and effects. Estuar Coast Shelf Sci 59:249-263

Li GZ, Liang W, Liu JH (2001) Features of underwater dynamic geomorphology of the Qinzhou Bay. Geogr Territ Res 17:70-75 (In Chinese)

Li CG, Xia YL, Dai HB (2015) Temporal analysis on spatial structure of mangrove distribution in Guangxi, China from 1960 to 2010. Wetland Sci 3:265-275 (In Chinese)

Liang GY (2014) Soil erosion evolution trends of Guangxi and analysis of causes. Guangxi Water Resources \& Hydropower Engineering 4: 71-73 (In Chinese)

Loder NM, Irish JL, Cialone MA, Wamsley TV (2009) Sensitivity of hurricane surge to morphological parameters of coastal wetlands. Estuar Coast Shelf Sci 84:625-636

Mudersbach C, Wahl T, Haigh ID, Jensen J (2013) Trends in high sea levels of German North Sea gauges compared to regional mean sea level changes. Cont Shelf Res 65:111-120

Pittaluga MB, Tambroni N, Canestrelli A, Slingerland R, Lanzoni S, Seminara G (2015) Where river and tide meet: The morphodynamic equilibrium of alluvial estuaries. J Geophys Res 120:75-94

Pye K, Neal A (1994) Coastal dune erosion at Formby Point, north Merseyside, England: Causes and Mechanisms. Mar Geol 119:39-56

Shi Z, Wang R, Huang MX, Landgraf D (2002) Detection of Coastal Saline Land Uses with Multi-Temporal Landsat Images in Shangyu City, China. Environ Manag 30:142-150

Tambroni N, Pittaluga MB, Seminara G (2005) Laboratory observations of the morphodynamic evolution of tidal channels and tidal inlets. J Geophys Res 110(F4). https://doi.org/10.1029/2004JF000243

Thomas CG, Spearman JR, Turnbull MJ (2002) Historical morphological change in the Mersey Estuary. Cont Shelf Res 22:1775-1794

Tian B, Wu W, Yang Z, Zhou Y (2016) Drivers, trends, and potential impacts of long-term coastal reclamation in China from 1985 to 2010. Estuar Coast Shelf Sci 170:83-90

Todeschini I, Toffolon M, Tubino M (2008) Long-term morphological evolution of funnel-shape tide-dominated estuaries. J Geophys Res 113(C5). https://doi.org/10.1029/2007JC004094

Tonis IE, Stam JMT, van de Graaf J (2002) Morphological changes of the Haringvliet estuary after closure in 1970. Coast Eng 44:191-203

Townend I (2005) An examination of empirical stability relationships for UK estuaries. J Coast Res 21:1042-1053

Van der Wal D, Pye K (2003) The use of historical bathymetric charts in a GIS to assess morphological change in estuaries. Geogr J 169:21-31

Van der Wal D, Pye K, Neal A (2002) Long-term morphological change in the Ribble Estuary, northwest England. Mar Geol 189:249-266

Wang Y, Dong P, Oguchi T, Chen S, Shen H (2013) Long-term (18422006) morphological change and equilibrium state of the Changjiang (Yangtze) Estuary, China. Cont Shelf Res 56:71-81

Wang YH, Tang LQ, Wang CH, Liu CJ, Dong ZD (2014) Combined effects of channel dredging, land reclamation and long-range jetties upon the long-term evolution of channel-shoal system in Qinzhou bay, SW China. Ocean Eng 91:340-349 
Wheeler P, Peterson J, Gordon-Brown L (2010) Long-term bathymetric effects of groyne array emplacement at Lakes Entrance, Victoria, Australia. Appl Geogr 30:126-140

Wu ZY, Saito Y, Zhao DN, Zhou JQ, Cao ZY, Li SJ, Shang JH, Liang YY (2016) Impact of human activities on subaqueous topographic change in Lingding Bay of the Pearl River estuary, China, during 1955-2013. Sci Rep 6:37742

Ya HZ, Xu YH, Li YC, Dong DX (2017) Effects of shoreline change on hydrodynamic environment in Qinzhou Bay. Guangxi Sci 24:311315 (In Chinese)
Zhang BH, Chen SL, Gu GC, Feng AP (2010) Formation and stability of tidal channels in Qinzhou Bay. Coast Eng 29:43-50 (In Chinese)

Zhang W, Xu Y, Hoitink AJF, Sassi MG, Zheng J, Chen X, Zhang C (2015) Morphological change in the Pearl River Delta, China. Mar Geol 363:202-219

Zhuang JL, Xu MB, Wang YB, Jiang FJ, Li YC, Chen XY, Chen B (2014) Response analysis of intertidal organism communities to environmental change in Qinzhou Bay. Guangxi Sci 21:381-388 (In Chinese) 